\title{
Applied theatre Ecology of practices
}

\section{Jenny Hughes and Helen Nicholson}

At high tide on the Thames on 13 June 2015 at II. 53 am a group of art activists began an unsanctioned twenty-five hour durational performance in the expansive Turbine Hall at Tate Modern, a large art gallery on the gentrified South Bank in London. Entitled Time Piece, this was the latest in a series of interventions by Liberate Tate, an art collective who stage performative protests against the oil industry's sponsorship of cultural organisations. Described as a 'textual intervention', seventy-five performers used charcoal to inscribe the concrete floor with passages and quotations from dystopian novels, environmental reports, slogans and non-fictional works about art, climate change and fossil fuel. Each performer scribbled silently, veiled and dressed in black, and when the gallery closed at Io pm, twenty activists continued their carefully choreographed work through the night, unimpeded by security guards or the police. By morning, when Tate Modern re-opened its doors, the Turbine Hall remained closed to visitors. When the tide turned at $12.55 \mathrm{pm}$ on I4 June, the performers left and the cleaning staff moved in.

We begin with this performative protest not because it is representative of all applied theatre, but because its concerns resonate with many of the ideas explored in this book. As a piece of activist art, Time Piece both invokes a long history of performative protest and also captures contemporary anxieties about the relationship between climate change, global capitalism, neoliberalism and the arts, all of which are debated by authors in this book. Beyond the substance of its environmental message, the performance illuminates deeper cultural responses to the contemporary landscape that are also articulated in this collection of essays. Time Piece reimagined synergies between time and the material world, recognising that temporality is experienced in multiple ways. Liberate Tate capture this impulse on their website, describing how Time Piece draws attention to the different temporal registers that affect lives as lunar time, tidal time, 
ecological time, geological time and all the ways in which we are running out of time'. 'The hunched figures dressed in black veils, quietly creating a rising tide of words on the floor, were like mourners marking a space by inscribing its relationship to lost time, a performative memorialisation of material life destroyed by practices of industrial excavation and economic exploitation driven by fossil fuel economies. Echoing many of the examples explored in this book, the performance drew attention to the geopolitics of place and was underscored by an impetus to re-make relationships between the human and non-human world. In the final moments of the short film of Time Piece, an applauding audience watch a gallery cleaner with his mop and bucket wash away the text, emphasising the impermanence of performance. Given that Liberate Tate habitually use social media to promote their vision for social change and to document their artistic interventions, it is significant that the last words to be wiped clear carry the hashtag, \#TimePiece.

Critical Perspectives on Applied Theatre arises from our shared perception that, as the twenty-first century moves into its third decade, applied theatre is shaping and is shaped by new conceptual paradigms that are not only responsive to contemporary concerns but are also influencing the ways in which socially engaged art and art-making are produced and understood. Gathered together in this collection are debates about theatre's relationship to temporality and cultural memory, the politics of place, environment and attachment, and the material and relational dimensions of human and non-human agency. Applied theatre emerges as a creative force that responds imaginatively to the ways in which the loci of power have become diffuse and fragmented in the twenty-first century, and to new questions about how increasingly nuanced ideas of authority can be harnessed for social change. As Liberate Tate testify, the Anthropocene has, if anything, made the political imperatives of applied theatre even more pressing. This book responds critically to these twenty-first century challenges, setting out fresh agendas by analysing creative forms of compassionate art-making that engage with post-humanist perceptions of a material world.

By connecting with a contemporary set of political vocabularies in this book, our ambition is not to set up a new orthodoxy, but to capture and interrogate some of the divergent practices that constitute applied theatre. Isabelle Stengers' idea of an 'ecology of practices' is particularly pertinent in this context, offering what she describes as 'tools for thinking':

An ecology of practices does not have any ambition to describe practices 'as they are'; it resists the master word of a progress that would justify their destruction. 
It aims at the construction of new 'practical identities' for practices, that is, new possibilities for them to be present, or in other words to connect. (2005: I86)

An ecology of practices promises to hold divergent and critical perspectives in conversation, enabling connections to be found. Crucially, Stengers suggests, there is 'no identity of a practice independent of its environment', and this implies that all practices are contingent on place and time. She suggests that a sense of belonging is integral to a researcher's toolkit, and it is significant that all authors represented in this book have chosen to write about contexts they know well, and in places to which they have attachment. The affective registers and intimacy of scale that this inspires lends the writing an autobiographical quality, perhaps particularly when the researchers are also working as artists.

This book is presented as a set of debates and practices that can be read in dialogue with each other. We have grouped the chapters into three parts, each of which gather together chapters that explore specific aspects of applied theatre: Histories and cultural memories; Place, community and environment; Poetics and participation. Curating chapters in this way is designed to help readers navigate the territory in different ways, either reading sequentially through the book or, to adapt Stengers' words, finding new possibilities to be present and to connect. In this introduction, we begin by exploring the 'practical identities' of applied theatre, and asking why it is time to consider critical perspectives on applied theatre. Following that, rather than introducing each section in turn, we consider two broad conceptual challenges that have emerged as central debates in the book. First, we examine the ways in which a new attentiveness to the historical is evident across many of the essays collected here, which, taken together, offer readings of applied theatre's relationship to memory, history and historiography from a series of resonant intersections between place and time. Second, we investigate how materialities of place and the politics of attachment are inviting new social imaginaries. The ecologies of practices in this book, therefore, reflect the different temporal dimensions of applied theatre, reaching to the past to understand the present and the future, reflecting on the dynamic between place and community, and also recognising that social change is always enacted in the material present of the here and now.

\section{Why critical perspectives?}

'Applied theatre' is now an established term and is widely associated with creative practices that engage with the social, educational and political 
functions of theatrical processes. As an 'ecology of practices' applied theatre is continually shifting and developing, with the consequence that it has not one identity but many practical identities, differently and appropriately nuanced according to context. As part of its richness, applied theatre is associated with a body of experimental theatre-making rather than a set of toolkits, and in universities applied theatre is a field of teaching and research that can no longer be described as emergent. This institutional acceptance comes, however, with its own set of disciplinary challenges, and the impetus behind this edited collection is to respond to some of these. One such challenge is economic; funders in all sectors and settings expect to see outputs, outcomes and evidence of the work's impact and efficacy, and students also hope to increase their 'employability' as a result of their expensive university education. In part, this economic imperative has upheld an emphasis on applied theatre as a mode of personal and social problem-solving in which predetermined goals are realised, and this can mean that applied theatre is conceptualised in ways that serve neoliberalism well. This lack of criticality can sometimes be obscured by an apparently activist rhetoric: applied theatre transforms, promotes well-being, improves quality of life, and moves people on. Notably, writing about applied theatre has often been preoccupied with a central tension between understanding itself as a force for imaginative resistance and as problematically entwined with networks of power and exploitation. Our invitation to authors was to develop critical perspectives that would begin to rebalance this necessary tension. A critical perspective starts from a recognition that theatre-making is inevitably entwined in networks of power and exploitation, however, it also encourages artists and researchers to seek out a presence in those networks that complements the resistant practices that are immanent there rather than adopting more acquiescent relations that flatten out practice and reflection.

By critical perspectives, then, we mean to provide an intellectual mapping of key practices, questions and debates that have shaped applied theatre. We also want to trouble the markers of applied theatre as a disciplinary space, identifying emergent areas of research and practice that reflect the complexity and richness of contingent practices. We aim to name such markers in this introduction and in the collection as a wholecountering, on the one hand, too easy accounts of the transformational powers of theatre and, on the other, apologetic expressions of applied theatre's political engagements and its aesthetics. Following Stengers' analysis, there are three kinds of critical perspectives that run through the collection. First, rather than presenting applied theatre as a 'discipline' and 
working to preserve or develop particular orthodoxies, 'master words' or narratives of progression, we offer a framing of applied theatre as an ecology of practices that make pragmatic, imaginative and contingent relations, connections, attachments and belongings. Second, a search for critical kinds of reflection and practice is a long-standing feature of applied theatre, and we welcome the engaged and at times impassioned writing in this collection that indicates a revitalisation of these resistant relations. As part of both of these perspectives, it is also noticeable that the essays in this book provide critical interrogations of practices that feature a new appreciation of the historical experiences that have shaped the material and immaterial environments of communities and artists over time.

The collection is remarkably consistent in terms of the absence of grand claims for theatre's transformational powers, and in the authors' refusal to make sharp distinctions between the aesthetic and social discourses of the practices they explore. There are signs of a new, measured and confident voice for applied theatre that is politically aware and reflexive. Finally, then, it is clear that the kinds of criticality evident in this book are stimulating new thinking about efficacy and aesthetics. Importantly, these essays are not in defence of the practices they depict, and nor are their arguments overwhelmed or reduced by consideration of the complex networks of power that those practices are embedded in. They make neither grand nor small claims, and instead are characterised by a growing awareness that, following Stengers, it is the 'staking' of a claim that is the problem, as it fails to notice a 'gathering' that occurs via an ecological perspective on practices that 'makes present ... something which transforms their relation to the stakes they have put up' (2005: I95). As part of this, the essays exhibit appreciation of the relationship between the artist and process of art-making as engaged in a social and material network that is reproduced, disturbed and reinvented by each theatrical happening. This collection provides a platform for dialogue about applied theatre by asking the kind of productive questions that will keep its borders open, developing advanced debate and discourse that is necessary to support its complexity and reinforce its status as a fluid ecology of practices.

\section{Histories and cultural memories}

By opening this chapter with Liberate Tate's Time Piece we hope to draw attention to the ways in which environmental concerns create an imperative to reconsider human relationships to time and place. One book used as 
part of the rising tide of words charcoaled onto the floor of the Turbine Hall was marine biologist Rachel Carson's 1950 bestseller The Sea Around $U s$, and a citation on the floor reminded spectators that a wave carries messages from the landscapes of the deep ocean as well as changing surface environments met along its journey, messages that travel via the ominous and omniscient force of tidal time: '[T]here is no drop of water in the ocean, not even in the deepest parts of the abyss, that does not know and respond to the mysterious forces that create the tide' (1989 [1950]: 149). Critical Perspectives on Applied Theatre mirrors the concerns of environmental artists by evidencing a new attentiveness to the operations of time in creative practice and in the histories of practices. In some essays, this attentiveness to the historical is present in explorations of how artists and communities have drawn on experiences of remembering and forgetting, presence and absence, recovery and loss in the processes of making theatre. In others, there is a valuing of intimate moments of encounter in a creative process, moments that are framed in ways that evidence their richness as modes of engaging with questions that have broad significance for this ecology of practices, and for cultural practice more generally.

There are two key perspectives on the historical that are present in this book, and both connect to our discussion of applied theatre in this introduction. First, applied theatre is seen as dangerously forgetful of its histories, and there is a connected search for histories that have as yet not been written; and, second, there is a move to create history by standing still in one place and time, and noticing how landscapes intervene in a conversation about time, a process which might also involve encounters with ghosts present in such landscapes. Baz Kershaw's essay opens the collection, and he reflects on applied theatre's increasingly established status. He examines a series of well-known works as well as student textbooks on applied theatre, drawing attention to historiographical insights, absences and omissions in these sources. He notes the predominance of micro-accounts of theatre projects that populate the literature, and his provocation to the field is clear. There is a need for comparative microanalyses inflected with holistic analysis and ecological principles', so as to create metahistories of theatre's engagements with global issues of ecological threat, political and economic crisis, and their networks of causation. Amongst other examples, Kershaw looks to a theatre practice that made use of stories from a now extinct South African tribe, archived more than Ioo years before, re-inserting those stories into landscapes marked by the presentabsence of that tribe (drawing on work by Mark Fleishman, also 
present in the collection). This layering of story and landscape is evocative and Kershaw's essay provides a series of impressionistic glances towards a historiographical practice that acknowledges human agency as a non-determinant and relational feature of meaning-making. In this practice multiple temporalities are all engaged in a conversation about the shapes and forms of survival (or not), and ghostly presences landscapes, forgotten people and extinct cultural practices - are invited into the conversation: 'the past is incessantly accessibly alive in some way or another and the future is never wholly an absence in histories of the present'. Here, to cite Prasenjit Duara, '[h]istory is the circulatory and dynamic repository of live possibilities for future actions' (2015: 9), a receptacle through which myths, narratives, memories, official and unofficial accounts are exchanged and reformulated.

The essays respond to this rich provocation by engaging with history in ways that are attentive to place, with historical reflections arising from particular landscapes and architectures important to applied theatre. Hughes' essay explores theatrical entertainments in a Victorian workhouse in Rochdale, United Kingdom, and she makes a case for the inclusion of theatrical forms of nineteenth century rational recreation, and temperance and Sunday School drama in the histories of applied theatre, complementing narratives that locate histories of applied theatre in modernist experimentation. Memories and archives are also used as creative sources for theatre projects, and WanJung Wang's essay provides an engaging analysis of theatre performances in city spaces of Southeast Asia. Her work is inspired by the forgotten, destroyed, invisible and disappearing memories of inhabitants whose homes are under threat from development. Paul Heritage and Silvia Ramos' account of the occupation of two abandoned wards of a psychiatric hospital in Rio, Brazil, by young artists from the favelas looks to the countercultural movement of the 1950s as a source of inspiration. Their essay is written as a series of letters to Brazilian psychiatrist Nise de Silveira (1905-99), whose pioneering efforts to develop creative psychiatric care in Rio de Janeiro are being revitalised by the artistic occupation carried out in the contemporary moment.

Applied theatre is an ecology of practices made from encounters with borders, with those encounters characterised by openness and commitment to a process of making relations rather than staking out a secure or fixed position. Stengers proposes an approach to the historical that refuses to make destruction of an existing position a condition of the new: 
It is clearly hard to think without reference to a kind of progress that would justify its past as a path leading to our present and future. The ecology of practices has this ambition. (2005: I85)

Ecological histories of practices might be made, then, by witnessing, collecting and gathering rather than overturning and discarding what has gone before. An understanding of applied theatre as a practice of 'gathering' multiple temporalities together rather than working in linear time seems most relevant, and this approach features in the essays written by Wan-Jung Wang, Paul Dwyer and Helen Nicholson. It becomes clear how multiple temporalities - a shifting between and across, allowing meaning and identity to emerge from the gathering together of many experiences of time, and relations to time, in one place - are engaged in applied theatre practices to different ends in contingent settings. And that the contingency of this time, this place is of utmost significance (and a source of resistance) for people living in the contexts of precarity that host each of these practices. Here, the historical might be experienced as a burden that needs to be negotiated as much as a resource for figuring a response to the present, with the creative practice of theatre engaging with it in a variety of ways. Negotiating historical burdens might be attended to by remembering, as in the examples examined by Wang, or by focusing on the present rather than on personal history, as in the project with immigrants explored by Sally Mackey, or by memorialising, as in the account of theatrical practices of reconciliation in Bougainville, Papua New Guinea, by Dwyer. Alternatively, the historical might need to be re-imagined altogether, as described by Nicholson in her account of a one-to-one performance practice that emerged when helping an elderly neighbour prepare to move into a care home. Here, theatre played a role in refiguring history and time into an assortment of receptacles for gathering and carrying the identities of a person safely over a change in her everyday life.

Discussions of history and time in this collection demonstrate attentiveness to how experiences of time unfold in the shaping of theatre practice, and to allow the temporal its own agency as part of a creative process. It is perhaps Dwyer's provocation to move towards a 'slower' applied theatre practice that is most striking in this regard, by which he means a practice that builds from dialogues with people and place over time (over decades, in his case). A cautionary modality is introduced here, in that Dwyer questions his own presence in a country that has suffered from a history of exploitation connected to his home country. In response, Dwyer slowed down time - allowing his practice to unfold as a fluid set of 
cultural and economic exchanges that were entirely unknown at the outset and where power dynamics were continually acknowledged and negotiated. This attention to the 'time' of time resists an urge to work towards the new and the utopic, and instead responds to how time, as an interrelation of human and non-human agency, shapes people and places. Time has an omniscience that influences the future of creative practice in unpredictable ways, and as such, demands to be included in the conversation.

\section{New materialities of applied theatre}

Woven through these essays is an interest in the productive relationship and sometimes tension - between human agency and the agentic capacities of the material world. Historically, as we have suggested, applied theatre has been primarily concerned with human agency, with the consequence that theatre practice has been harnessed to various forms of individual improvement or societal action. What these histories share is a way of seeing the material world as an inert backdrop to a human-centred social drama rather than as significant and a presence. Perhaps for the first time in applied theatre this collection of essays shows an emergent engagement with both economic materialism and the inequitable distribution of wealth, and the political implications of understanding the material world as an active force in everyday life. This new attention to the materialist ontologies of applied theatre is noted by Kershaw, who observes that human memory is embodied as well as linguistic, and cites the political theorist Jane Bennett's concept of vital materialism (2010: I4-17), an idea that recognises that some forms of matter have their own agency and defy human will. Although not all authors gathered here would align themselves with new materialist theories, the book is marked by the attention paid to the sensory, embodied, affective and place-based qualities of applied theatre as one way to erode fixed binaries between the human and non-human world and to recognise their reciprocity.

Inevitably this emphasis on the materialities of applied theatre has involved challenging some familiar orthodoxies; the progressive spirit of the nineteenth and twentieth centuries was marked by the view that greater advancement in self-knowledge and rational understanding of the world would improve the human condition. This way of thinking led theatre-makers to develop practices designed to encourage rational debate, with the expectation that enacting solutions to shared social problems would enable participants to challenge or resist their oppressions. Although this approach remains one aspect of politically engaged 
theatre-making, it is noticeable that that this cause-and-effect linearity ignored or underplayed the aesthetics of duration, place and attachment explored by authors represented in this book. Sally Mackey's chapter marks such a shift in emphasis, where she instates place as a performative landscape that carries its own agency in a creative process and suggests how invitations to participants to attend to the quotidian and sensed environment in imaginative and playful ways 'thickens' places for new residents. Kathleen Gallagher shares Mackey's interest in the materialities of everyday life and the sensory qualities of theatre-making in her work with homeless youth in Toronto, Canada. Gallagher applied the 'aesthetic of talk' to this creative project, a process that recognised the limits of theatres of debate and acknowledges that the affective register has political force.

Many of the essays in the collection offer an analysis that is responsive to the politics of scale as well as to the affective, sensory and place-based dynamics of human and non-human interaction in creative practice. Gallagher investigates the relationship between applied theatre as a micropolitical intervention and wider socio-structural analyses. She describes this relationship as a 'precarious dance between personal story and structural change', a phrase that scopes out a useful terrain for ongoing investigations of both the poetics of participation and the non-linearity of social change. From his position in South Africa, Mark Fleishman is similarly concerned with the material politics of scale, observing that the inequalities that continue to define everyday life in South Africa play a significant part in how questions of citizenship and authority are enacted and performed in the process of community-based theatre-making. By troubling hierarchical notions of authority, however, Fleishman suggests that the process of collaboration between participants and theatre-makers creates a temporary micro-community, fostering an active citizenship that is sited in the material practices of theatre-making and situated in the complexity of its political, social and cultural setting. In this configuration, and in the terms described by D. Soyini Madison in this collection, social justice becomes a form of labour, poetically and politically poised between the storied identities and micropolitics of everyday life, and the macrostructures of material inequalities. As such, each of these essays confirm Diana Coole and Samantha Frost's observation that new materialist thought 'compels us to think of causation in ... complex terms; to recognise that phenomena are caught in a multiple of interlocking systems and forces and to consider anew the location and nature of capacities for agency' (2010: 9). 
Across the collection authors suggest that there is an urgent need to respond to the catastrophic ways in which the material world sometimes asserts itself into everyday life. The chapters written by Syed Jamil Ahmed and Peter O'Connor demonstrate how, in the face of environmental disasters, theatre-makers can respond in different ways. Both Ahmed and O'Connor debate the politics of neoliberalism, with O'Connor giving an account of the urgent attention to the present engendered by the earthquakes in Christchurch in 20IO-II. His essay pays attention to the way a disaster an eruption and disruption of the temporal - can become a focus for competing forms of theatrical narrative, and argues for the necessity of theatre projects that explicitly disrupt neoliberal disaster capitalism's territorialism and in ways that allow communities into decision-making processes about their futures. Writing about the devastating consequences of climate change on his home country of Bangladesh, Ahmed provides a searing critique of how some forms of applied theatre are, perhaps unwittingly, complicit in upholding neoliberalist politics of self-care and selfresponsibility in the face of ecological disaster rather than addressing the materialist politics that is causing this crisis. Ahmed points out that the neoliberal homo economicus exists everywhere, and the outdated view that there are clear binaries between the privileged, colonising and capitalist West and the colonised, impoverished and subaltern 'Rest' fails to acknowledge how everyone is reciprocally implicated in neoliberalism, from Bangladeshi farmers seeking the best prices for their produce on their mobile phones to well-intentioned Western theatre practitioners wishing to work in impoverished countries. In offering an alternative to the interventionist practices he associates with applied theatre, Ahmed suggests that the neoliberal idea of self-care might be 're-visioned as social care' through storytelling. Ahmed's voice is passionate, polemical and persuasive, and his contribution to the ecology of practices offers a powerful tool not only to think further about responses to climate change but also to consider how theatre-makers are always and inevitably embroiled in the materialist politics that neoliberalist agendas appear to evade or ignore.

Throughout this collection of essays, authors articulate experiences of belonging and feelings of attachment to the contexts of practice in ways that are ethically sensitive. Applied theatre requires reciprocity, a process that is often politically complex and emotionally challenging. These relations of reciprocity are explored by Helen Nicholson in the final essay in this collection, where she argues for a new ontology of applied theatre as a practice of relation. A relational ontology of applied theatre opens questions about how future theatre-makers might attend to place and 
time, both contesting and problematising its limits as well as in ways that open up new social imaginaries. Her argument again draws attention to how theatre-making offers the possibility of figuring a relation to time and place that is in step with the multiple temporalities that shape material worlds, resisting separation into autonomous components that might be lifted out of context and reproduced elsewhere. In answer to pressures to describe applied theatre using the discourses of economic productivity noted earlier and contested throughout this collection, what emerges here is an understanding that a changed world is no longer solely an outcome of human action, if it ever was. Instead theatre-makers create worlds of shifting scales and measures - in which small objects sustain extraordinary resonances, unpolished and improvised artistic experiences make profound political statements, insignificant moments of encounter alter dimensions of place and time, and established forms and meanings are swept away in an instant. And in that spirit, we bring our own attempt to scale and measure the debates opened in this book to a close and offer it up to readers for consideration as an artefact that carries meaning only in relation to their own contingencies of time and place.

\section{References}

Bennett, J. 2oro. Vibrant Matter: A Political Ecology of Things. London: Duke University Press.

Carson, R. 1989 [1950]. The Sea Around Us. Oxford: Oxford University Press.

Coole, D. and Frost, S. (eds.) 20ro. New Materialisms: Ontology, Agency, and Politics. Durham and London: Duke University Press.

Duara, P. 20I5. The Crisis of Global Modernity: Asian Traditions and a Sustainable Future. Cambridge: Cambridge University Press.

Liberate Tate. Time Piece. www.facebook.com/liberatetate/videos/1622725534633 $402 /$. Last accessed 29 July 2015.

Stengers, I. 2005. 'Introductory notes on an ecology of practices'. Cultural Studies Review II.I: I83-196. 